\title{
Evaluation of an extracurricular program for students interested in rural and public health
}

\author{
Do-Hwan Kim', Ah Reum An², Eun Jeong Kim', Jong-Koo Lee ${ }^{3}$ and Seung-Hee Lee ${ }^{1}$ \\ ${ }^{1}$ Department of Medical Education, Seoul National University College of Medicine, ${ }^{2}$ Public Health Medical Service, \\ Seoul National University Hospital, and ${ }^{3} \mathrm{JW}$ Lee Center for Global Medicine, Seoul National University College \\ of Medicine, Seoul, Korea
}

Purpose: The problem regarding the geographic imbalance of the physician workforce has been a long-standing problem in South Korea. Additionally, rural medicine and public health have been marginalized across whole undergraduate curriculums. The aim of this study was to evaluate the effectiveness of an extracurricular program targeting medical students interested in rural and public health.

Methods: A 2-day extracurricular program was held twice in 2015 and 2016. A total of 53 students were selected among eighty students who voluntarily applied to participate in the program. The effectiveness of the program was evaluated by pre- and post-program surveys.

Results: The overall satisfaction for the program was 5.35 out of 6 . The participants showed a significant improvement in perception of the clerkship experience in a rural and public health care setting as well as the importance of rural medicine and public health in South Korea.

Conclusion: In conclusion, this study showed the acceptability of a short-term extracurricular program for medical students interested in rural and public health.

Key Words: Rural health, Public health, Medical students, Curriculum, Undergraduate medical education

\section{Introduction}

A geographic imbalance in the physician workforce has been a long-standing problem. This phenomenon exists not only across the globe but also at the country level [1]. South Korea, where medical resources are mainly concentrated in urban and metropolitan areas, is no exception. This mismatch of resources to healthcare needs, however, becomes even more complicated in
South Korea because the proportion of medical care covered by the public sector, primarily responsible for the rural and underserved population, is significantly low compared to other developed countries [2].

To effectively address the problem of rural physician shortage, it has been well-argued that the strategies should cover a wide range of the medical education continuum to constitute a "pipeline" including selection, education, recruitment, and retention [3]. However, in South Korea, undergraduate medical education (UME) is
Received: February 8, 2017 • Revised: April 7, 2017 • Accepted: May 8, 2017 Corresponding Author: Seung-Hee Lee (http://orcid.org/0000-0001-8672-5253) Department of Medical Education, Seoul National University College of Medicine, 103 Daehak-ro, Jongno-gu, Seoul 03080, Korea

Tel: +82.2.740.8406 Fax:+82.2.741.1186 email: 1shcho@snu.ac.kr
Korean J Med Educ 2017 Jun; 29(2): 111-116.

https://doi.org/10.3946/kjme.2017.58

eISSN: 2005-7288

(C) The Korean Society of Medical Education. All rights reserved. This is an open-access article distributed under the terms of the Creative Commons Attribution Non-Commercial License (http:// creativecommons.org/licenses/by-nc/3.0/), which permits unrestricted non-commercial use, distribution, and reproduction in any medium, provided the original work is properly cited. 
not sufficiently prepared to train adequate physicians to be engaged in rural and public health (RPH). In fact, $\mathrm{RPH}$ has been marginalized across the whole curriculum both in premedical and medical courses thus far [4,5].

Given the current challenges originated from a lack of $\mathrm{RPH}$ education in UME, it is necessary to develop and implement a new course or program for medical students. While evidence from many countries consistently shows that a rural background of medical students is positively correlated with choosing a rural career [6], the effectiveness of an educational intervention is less evident and frequently dependent on the context in which it is implemented [1]. Although there have been several studies reporting on the effectiveness of those programs conducted in Japan or Australia [7], it would be worth examining from the perspective of a South Korean context.

In this study, we piloted a 2-day extracurricular program targeting students interested in $\mathrm{RPH}$ and investigated the changes in the perceptions of the participants related to various aspects of RPH before and after completing the program.

\section{Subjects and methods}

\section{Program and participants}

The name of the program was the Camp for Regional Medicine (Jiyeog-uiryo-himang-camp in Korean) and held twice in July 2015 and August 2016. Specific dates were determined by considering the typical period and length of the summer vacation of the medical schools for the purpose of maximizing the pool of potential participants. The program objectives were threefold: (1) providing the general concepts of RPH, (2) assessing the educational needs, and (3) examining the changes in perceptions on RPH (Table 1). To achieve these, current and former experts, who have abundant practical experiences in the RPH area, were invited to lectures and panel discussion. Two workshops were conducted for a needs assessment, and finally the program was evaluated by a pre- and post-program survey.

The program was open to all premedical and medical students in South Korea regardless of their grades. Participants were selected through iterative discussions

Table 1. Overview of the Program

\begin{tabular}{|c|c|c|}
\hline Program objectives & Types of activities & Theme of the activities \\
\hline $\begin{array}{l}\text { Obj. 1. Providing general } \\
\text { concepts of RPH }\end{array}$ & Lecture & $\begin{array}{l}\text { L1. Doctor's role as a rural physician } \\
\text { L2. Basic understanding of } R^{a} H^{b /}\end{array}$ \\
\hline & $\begin{array}{l}\text { Panel discussion (with five experts, } \\
\text { no pre-established agenda) }\end{array}$ & $\begin{array}{l}\text { P1. Current state of rural medicine in Korea } \\
\text { P2. The role of public health service } \\
\text { P3. How to develop career as a rural physician }\end{array}$ \\
\hline $\begin{array}{l}\text { Obj. 2. Assessing the educational } \\
\text { needs of students in RPH }\end{array}$ & $\begin{array}{l}\text { Consensus workshop method }{ }^{\text {bl }} \\
\text { Group discussion }^{\text {bl }}\end{array}$ & $\begin{array}{l}\text { W1. What competencies are required for a rural physician? } \\
\text { W2. How should medical school faculties educate future rural } \\
\text { physicians? }\end{array}$ \\
\hline $\begin{array}{l}\text { Obj. 3. Examining the students' } \\
\text { change in perception on } \\
\text { RPH }\end{array}$ & $\begin{array}{l}\text { Evaluation (pre- and post-program } \\
\text { survey) }\end{array}$ & $\begin{array}{l}\text { S1. Perception of the importance of RPH } \\
\text { S2. Perception of clinical clerkship in different settings } \\
\text { S3. Perception of educational policy related to RPH } \\
\text { S4. Satisfaction with the program }\end{array}$ \\
\hline
\end{tabular}

Obj.: Object, RPH: Rural and public health, L: Lecture, P: Panel discussion, W: Workshop, S: Survey.

${ }^{a)}$ These activities were scheduled for day $1,{ }^{\text {bl }}$ These activities were scheduled for day 2. 
among researchers based on the reasons for application and previous experiences related to $\mathrm{RPH}$. In addition, students who entered medical school through the Regional Talents Admissions (Jiyeog-injae-jeonhyeong in Korean, RTA) were given more consideration.

\section{Program evaluation}

The pre- and post-program surveys used for evaluation of the program covered four themes: (1) overall satisfaction, (2) perception of the importance of $\mathrm{RPH}$, (3) perception of clinical clerkship in different settings, and (4) perception of related educational policy. To ensure the validity of the surveys, the items were developed through iterative discussion among researchers considering the goals and contents of the program. The two surveys were identical, except for one item which was included only in the post-program survey to check overall satisfaction with the program.

\section{Analysis of data}

IBM SPSS Statistics for Windows ver. 20.0 (IBM Corp., Armonk, USA) was used for the quantitative analysis. Because the surveys were conducted anonymously, the change in perception was analyzed by independent sample $\mathrm{t}$-test. A p-value less than 0.05 was considered statistically significant.

\section{Ethics statement}

The study protocol was approved by the Institutional Review Board (IRB) of Seoul National University College of Medicine (IRB number: C-1512-132-731). Informed consent was waived by the IRB.

\section{Results}

\section{Participants}

The total number of participants was 53, and $39.6 \%$ of those were male. Their mean age was 24.7 years (min, 18 years; max, 37 years). Among them, 52.8\% had entered medical school through the Undergraduate-Entry Program, and $17.0 \%$ had entered through the RTA. The premedical students and medical students comprised $30.2 \%$ and $69.8 \%$ of the total participants, respectively. The provinces from which they graduated high school were also distributed throughout most of the country except for three provinces, South Jeolla, North Jeolla, and North Chungcheong. The demographic features of the 80 students who initially applied to the program were comparable to those of the entire participants.

\section{Program evaluation}

In the post-program survey, the total scores on overall satisfaction were 5.35 out of 6 (Table 2). When comparing the results of the pre- and post-survey, their perception of the importance of RPH had improved both for rural medicine $(\mathrm{p}=0.048)$ and public health $(\mathrm{p}<0.001)$. Regarding the perception of clinical clerkship in various settings, although there was no significant change in their intention to do a clinical clerkship in a metropolitan area or major city, their perception towards a clerkship in a smaller community, such as a county (gun in Korean) or town (eup or myeon in Korean) was significantly improved after the program $(\mathrm{p}=0.018$ and $\mathrm{p}=0.041$, respectively). Similarly, their intention to do a clinical clerkship in a primary care setting was greatly enhanced $(\mathrm{p}=0.004)$ while their preference for secondary and tertiary hospitals remained almost the same. Lastly, they became more positive about the effectiveness of RTA ( $p=0.001$ ). 
Table 2. Pre- and Post-Evaluation of the Program $(\mathrm{N}=53)$

\begin{tabular}{|c|c|c|c|}
\hline Item & $\begin{array}{l}\text { Pre-program } \\
\text { score }\end{array}$ & $\begin{array}{l}\text { Post-program } \\
\text { score }\end{array}$ & p-value \\
\hline \multicolumn{4}{|l|}{ S1. Satisfaction with the program } \\
\hline Q1. Overall satisfaction with the program ${ }^{\text {al }}$ & $\mathrm{N} / \mathrm{A}$ & $5.35 \pm 0.68$ & $N / A$ \\
\hline \multicolumn{4}{|l|}{ S2. Perception of the importance of RPH } \\
\hline 02-1. Importance of rural medicine in South Korea ${ }^{b /}$ & $5.04 \pm 0.66$ & $5.29 \pm 0.64$ & 0.048 \\
\hline Q2-2. Importance of public health in South Koreabl & $4.92 \pm 0.68$ & $5.43 \pm 0.57$ & $<0.001$ \\
\hline \multicolumn{4}{|l|}{ S3. Perception of clinical clerkship in different settings } \\
\hline Q3-1. Intention to do a clinical clerkship in metropolitan areas ${ }^{\mathrm{cl}}$ & $4.06 \pm 1.74$ & $4.24 \pm 1.52$ & 0.583 \\
\hline Q3-2. Intention to do a clinical clerkship in major cities ${ }^{c \mid}$ & $3.56 \pm 1.67$ & $3.73 \pm 1.43$ & 0.586 \\
\hline Q3-3. Intention to do a clinical clerkship in a county (gun in Korean) ${ }^{c l}$ & $2.43 \pm 1.04$ & $2.98 \pm 1.24$ & 0.018 \\
\hline Q3-4. Intention to do a clinical clerkship in a town (eup or myeon in Korean) ${ }^{\text {cl }}$ & $2.28 \pm 1.10$ & $2.76 \pm 1.25$ & 0.041 \\
\hline Q4-1. Intention to do a clinical clerkship in a tertiary hospital ${ }^{c^{\prime}}$ & $4.65 \pm 1.61$ & $4.67 \pm 1.42$ & 0.966 \\
\hline Q4-2. Intention to do a clinical clerkship in a secondary hospital ${ }^{c^{l}}$ & $3.24 \pm 1.53$ & $3.76 \pm 1.41$ & 0.076 \\
\hline Q4-3. Intention to do a clinical clerkship in a primary care clinic $^{c /}$ & $2.41 \pm 1.22$ & $3.20 \pm 1.43$ & 0.004 \\
\hline \multicolumn{4}{|l|}{ S4. Perception of related educational policy } \\
\hline $\begin{array}{l}\text { 05. Inclination to participate in a RPH-related extracurricular program during the } \\
\text { vacation period }^{\text {d) }}\end{array}$ & $2.83 \pm 1.12$ & $3.10 \pm 1.27$ & 0.252 \\
\hline Q6. Effectiveness of the Regional Talents Admissions ${ }^{\mathrm{e}}$ & $3.21 \pm 1.18$ & $3.94 \pm 1.07$ & 0.001 \\
\hline Q7. Inclination to apply for a compulsory service bonded scholarship ${ }^{\text {fl }}$ & $2.40 \pm 1.12$ & $2.47 \pm 0.92$ & 0.743 \\
\hline 08. Inclination to apply to a RPH specified medical school ${ }^{9 l}$ & $3.67 \pm 1.18$ & $3.65 \pm 1.29$ & 0.915 \\
\hline
\end{tabular}

N/A: Not available, RPH: Rural and public health.

a) 1: Very unsatisfied-6: Very satisfied, ${ }^{\text {b) }} 1$ : Not important at all-6: Absolutely important, ${ }^{\text {c) }} 1$ : No intention to participate in, 2: Affirmative for 1-3 months in total, 3: Affirmative for 4-6 months in total, 4: Affirmative for 7-9 months in total, 5: Affirmative for 10-12 months in total, 6: Affirmative for more than 13 months in total, ${ }^{d 1} 1$ : No intention to participate in, 2: Affirmative for spending 1 week every vacation, 3: Affirmative for spending 2 weeks every vacation, 4: Affirmative for spending 3 weeks every vacation, 5: Affirmative for spending 4 weeks every vacation, 6: Affirmative for spending more than 5 weeks every vacation, ${ }^{\text {el }} 1$ : Will have no impact at all-6: Will have a strong impact, ${ }^{\text {fl } 1} 1$ : No intention to apply, 2 : Will apply if the compulsory service is less than 2 years, 3 : Will apply if the compulsory service is less than 4 years, 4: Will apply if the compulsory service is less than 6 years, 5 : Will apply if the compulsory service is less than 8 years, 6: Will apply if the compulsory service is less than 10 years, ${ }^{91} 1$ : No intention to apply at all-6: Will certainly apply.

\section{Discussion}

In this study, we conducted a 2-day extracurricular program targeting students who were interested in $\mathrm{RPH}$. The results of the program suggested that it is possible to make changes to the perception of students in a positive way by providing this type of extracurricular program.

In terms of demographics, the participants were widely distributed regarding variables such as gender, age, and year in medical school. Although the absolute number of participants was limited, this result implies that there is current widespread concern about the $\mathrm{RPH}$ problem among medical students. It is particularly encouraging because the enhanced diversity of physicians could contribute to adequate provision of care by promoting equity and addressing disparities among these subpopulations [8].

After completing the program, the perception of the participants changed in a more favorably way regarding the importance of rural medicine as well as public health after completing the program. Particularly, it is worth mentioning that the perceived importance of $\mathrm{RPH}$ was 
already as high as around five out of six even in the pre-program survey. In addition, students' intention to participate in a clerkship in a smaller region and primary care setting was significantly improved while their preferences for a larger region or tertiary hospital remained unchanged. This positive change related to clerkship in a rural and primary care setting is encouraging, provided that the rural clerkship contributes to higher student satisfaction, academic achievement, and future rural practice compared to their urban counterpart [6]. In a long-term perspective, it has been also shown that a relevant learning experience in an extracurricular program increases the likelihood of choosing primary care or practice at underserved populations in their career decision making [9]. In brief, considering that changes in perception may lead to further changes in behavior, our finding suggests that this type of $\mathrm{ex}^{-}$ tracurricular program might be an acceptable and effective educational approach for medical students interested in RPH. For future research, development of a longitudinal program or exploration of the long-term effect of a program would be needed.

The main advantage of this 2-day workshop program, which appears to contribute to the change in perception, would be its participant-oriented approach. We deliberately limited didactic lectures to 2 hours in total. Instead, sharing of diverse experiences and opinions among the students was emphasized throughout the program. Moreover, students reflected on their firsthand experience and the problems in reality during the discussion, which is consistent with the principal motivating factors of an adult learner.

Despite its advantages, this study has several limitations. First, the limited number of students who participated in the program may not be enough to generalize the findings. However, although the number of participants was small, the composition was demograph- ically widely distributed. Moreover, considering that the percentage of medical students who prefer public health medicine or community health has often been reported to be as low as around 1\% [10], the actual number of students considering a RPH career in South Korea also might not be large in the first place. Second, because it was a short extracurricular program, the long-term effectiveness cannot be guaranteed. Nevertheless, our findings show early promise of success and could be used as baseline data for the development of longitudinal programs. Lastly, our findings could have been influenced by the self-selected nature of the voluntary participants. Considering these limitations, therefore, the development and evaluation of similar programs would be needed to confirm the generalizability of the study.

\section{ORCID:}

Do-Hwan Kim: http://orcid.org/0000-0003-4137-7130;

Ah Reum An: http://orcid.org/0000-0002-2070-430X;

Eun Jeong Kim: http://orcid.org/0000-0002-8935-2103; Jong-Koo Lee: http://orcid.org/0000-0003-4833-1178; Seung-Hee Lee: http://orcid.org/0000-0001-8672-5253

Acknowledgements: The authors acknowledge all participants who voluntarily and actively participated in the program.

Funding: This work was supported by a project fund from the Presidential Committee on Regional Development.

Conflicts of interest: None.

\section{References}

1. Wilson NW, Couper ID, De Vries E, Reid S, Fish T, Marais BJ. A critical review of interventions to redress the inequitable distribution of healthcare professionals to rural and remote areas. Rural Remote Health 2009; 9: 
1060.

2. OECD health statistics 2015 [Internet]. Organization for Economic Cooperation and Development; c2015 [cited 2016 December 16]. Available from: http://www.oecd.org/ health/health-systems/Focus-Health-Spending-2015.pdf.

3. Geyman JP, Hart LG, Norris TE, Coombs JB, Lishner DM. Educating generalist physicians for rural practice: how are we doing? J Rural Health 2000; 16: 56-80.

4. Park EW. Premedical students' experiences in communityoriented primary care. Korean J Med Educ 2013; 25: 229-237.

5. Kim SH, Yang EB, Ahn DS, Jeon WT, Lyu CJ. The present conditions of clinical clerkship management in Korea. Korean J Med Educ 2009; 21: 373-383.

6. Brooks RG, Walsh M, Mardon RE, Lewis M, Clawson A. The roles of nature and nurture in the recruitment and retention of primary care physicians in rural areas: a review of the literature. Acad Med 2002; 77: 790-798.

7. Matsumoto M, Kajii E. Medical education program with obligatory rural service: analysis of factors associated with obligation compliance. Health Policy 2009; 90: 125-132.

8. Cohen JJ, Gabriel BA, Terrell C. The case for diversity in the health care workforce. Health Aff (Millwood) 2002; 21: 90-102.

9. Kost A, Benedict J, Andrilla CH, Osborn J, Dobie SA. Primary care residency choice and participation in an extracurricular longitudinal medical school program to promote practice with medically underserved populations. Acad Med 2014; 89: 162-168.

10. Svirko E, Goldacre MJ, Lambert T. Career choices of the United Kingdom medical graduates of 2005, 2008 and 2009: questionnaire surveys. Med Teach 2013; 35: 365-375. 